\title{
Finite element analysis of prosthetic knee joint using ANSYS
}

\author{
C. Shashishekar ${ }^{1}$ \& C. S. Ramesh ${ }^{2}$

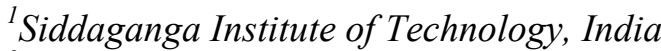 \\ ${ }^{2}$ P.E.S. Institute of Technology, India
}

\begin{abstract}
Degenerative arthritis is a disease that affects the line cartilage of the knee joint. It causes severe pain in the joint and may require a replacement surgery of the affected knee with artificial components. The aim of this research was to study the distribution of contact stresses in prosthetic knee joints made out of polyethylene chopped carbon fibre composite and conventional polyethylene. Commercially available software (ANSYS 8.1) was used in numerical experiments. The effect of the sagittal radius, flexion angles and external load on stresses in the joint were investigated in numerical experiments. Results showed lower contact stresses in the tibial part of the polyethylene chopped carbon fibre composite artificial joint compared to the tibia made out of polyethylene.

Keywords: tibia, knee joint, arthritis, sagittal radius, flexion angle.
\end{abstract}

\section{Introduction}

Degenerative arthritis of the knee joint is a disease that affects the line cartilage of the tibia and the femur. It causes severe pain and may require a replacement surgery of the affected knee with artificial components. Artificial joints should satisfy certain design requirements, i.e., they should be ergonomical and biocompatible. During activation, stresses are developed at the interface of joint, which in turn dictates the performance of the joint. The intensity of the stresses developed depends on several factors like, sagittal radius, flexion angle, material of tibia and femoral components and load acting on the bearing surface of the joint. To ensure the stress intensity, it is important to optimise the design of prosthetic knee joint. In this regard, FEM the most powerful numerical tool can be used to optimise the design. The sagittal radius is varied from $40-60 \mathrm{~mm}$ and the flexion angles of $0^{\circ}, 20^{\circ}$, and $40^{\circ}$ have been considered. The thickness of tibia 
was maintained constant and the materials used in the present investigation for analysis of joint are polyethylene and polyethylene chopped carbon fiber composite for tibia and alumina ceramic for femoral component [1]. The aim of the study is to investigate the impact of sagittal radius, flexion angle, load and materials of tibia on the stresses developed.

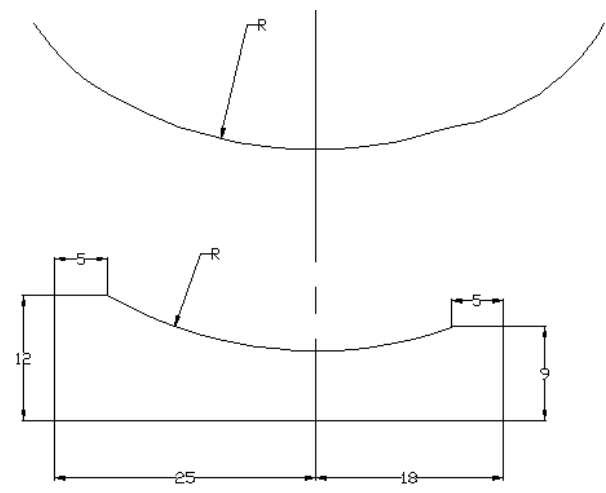

Figure 1: $2 \mathrm{D}$ view of tibia and femoral components.

\section{Methods}

The finite element method (FEM) is a widely used numerical technique to analyse stress-strain states in various biomedical devices and in prosthetic bone joints, in particular. Accurate geometric models of the tibial and femoral components of artificial knee joint were constructed using ANSYS software. Two dimensional diagrams of the femoral and tibia components of 40, 50 and 60 (mm) sagittal radius were generated and extruded in the $z$ - axis [2]. Polyethylene and polyethylene chopped carbon fibre were used to model the tibia part, and alumina ceramic to model the femoral part of the joint.

The finite element model was generated by meshing the solid model with 45 brick elements (Fig. 2). The tibial component was constrained in all degrees of freedom at its lower surface. The femoral component was rigidly fixed. A compressive load was applied to the femoral component at the bearing points at different flexion angles. The applied load varied from 500 to $2667(\mathrm{~N})[1,3]$. The relaxed joint with different values of the sagittal radius to match the posterior conformity with the femoral component was evaluated. Stresses were analysed for different femoral-tibial alignment positions.

\section{Results and discussion}

\subsection{Effect of sagittal radius on von Mises and maximum shear stress}

An increase in the sagittal radius resulted in increase in the Von Mises and maximum shear stresses (Figs. 3, 4). It did not depend on material properties 


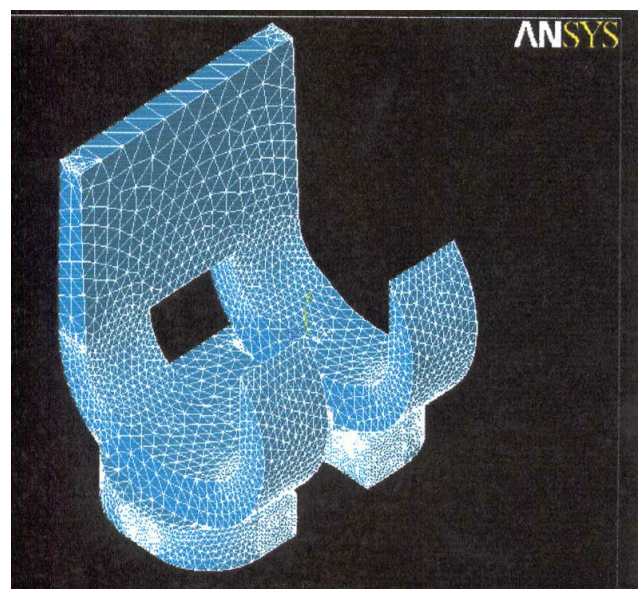

Figure 2: $\quad$ Finite element model of the artificial knee joint.

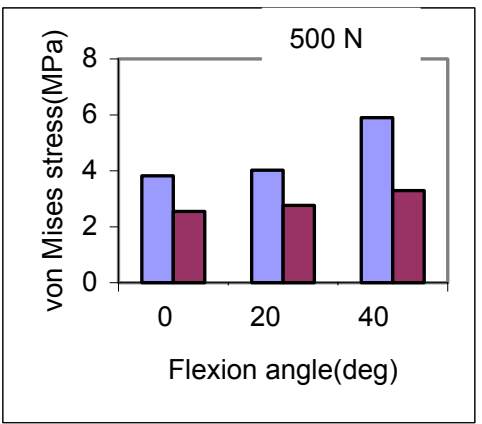

Sagittal radius $40 \mathrm{~mm}$

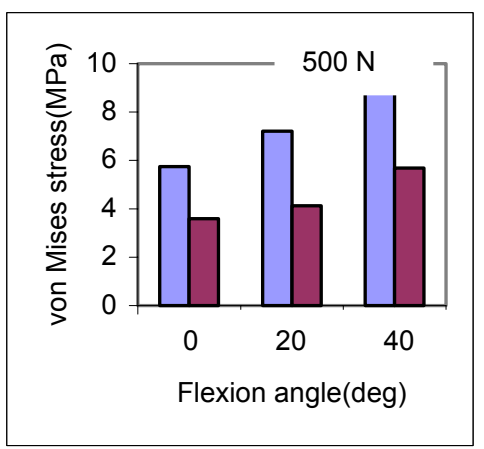

Sagittal radius $60 \mathrm{~mm}$

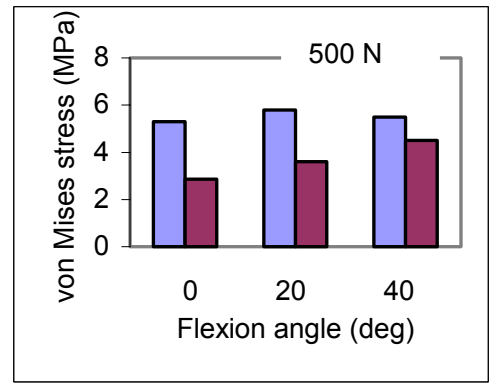

Sagittal radius $50 \mathrm{~mm}$

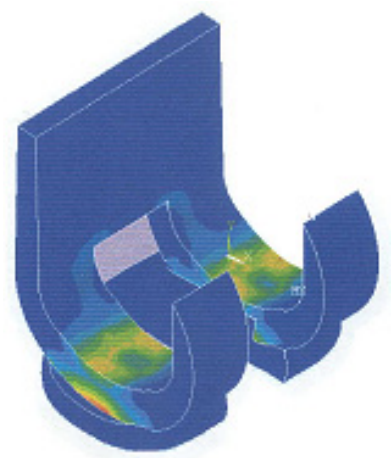

von Mises stress contour

Figure 3: $\quad$ von Mises stress for different sagittal radii. 
under investigation. This could be attributed to the fact that an increase in the sagittal radius results in increase in the contact area that led to higher bearing pressure and higher stresses.

\subsection{Effect of Flexion angle on von Mises stress and maximum shear stress}

The von Mises stress increased with the rise in the flexion angle (Fig. 3). This was due to the increase in the contact area. The maximum shear stress decreased with increase in the flexion angle (Fig. 4).

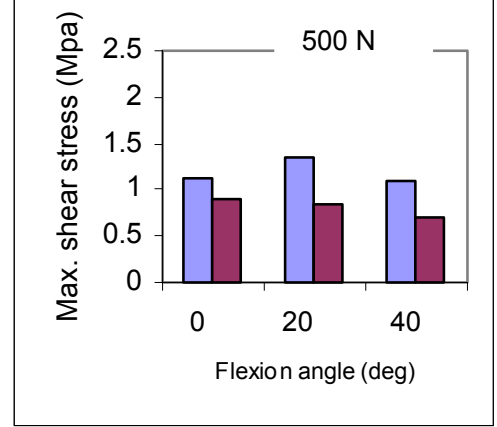

Sagittal radius $40 \mathrm{~mm}$

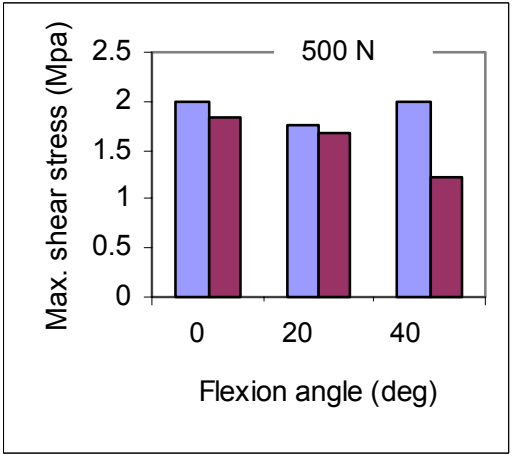

Sagittal radius $60 \mathrm{~mm}$

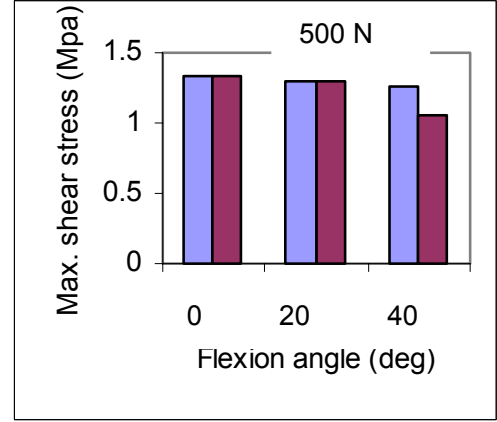

Sagittal radius $50 \mathrm{~mm}$

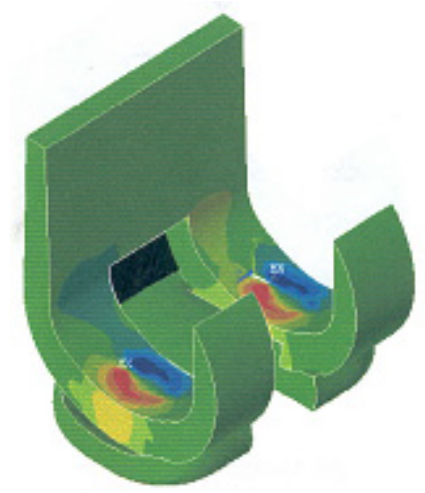

Maximum shear stress contour

Polyethylene

Polyethylene chopped Carbon Fiber

Figure 4: $\quad$ Maximum shear stress for different sagittal radii.

\subsection{Effect of load and material properties on von Mises stress and maximum shear stress}

An increase in the sagittal radius resulted in increased stress levels that correlated with the load level (Figs. 5, 6). It was observed that the polyethylene chopped carbon fiber composite material produced lower stresses in the artificial knee 
joint. At the maximum load of $2667 \mathrm{~N}$ the reduction in the stress level for polyethylene chopped carbon fibre material is by $15 \%$ for the maximum shear stress, and $32 \%$ for the von Mises stress, compare to the result obtained at zero degree of flexion angle and at $40 \mathrm{~mm}$ of sagittal radius, was recorded (Figs. 7, 8). This was related to mechanical properties of polyethylene chopped carbon fibre.

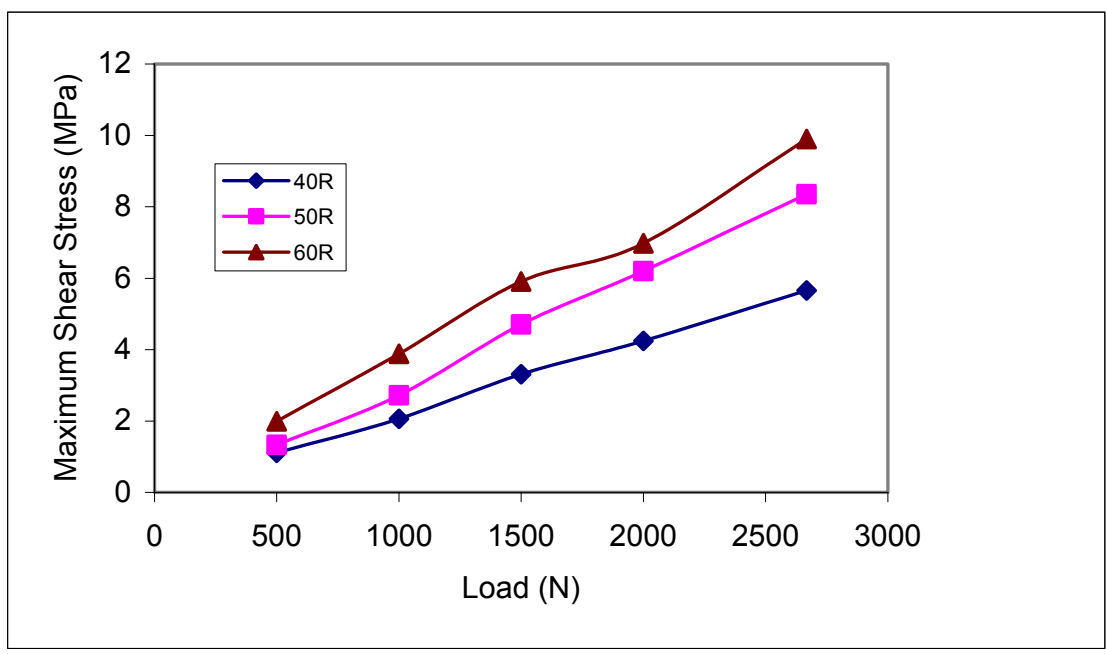

Figure 5: Maximum shear stress for different loads.

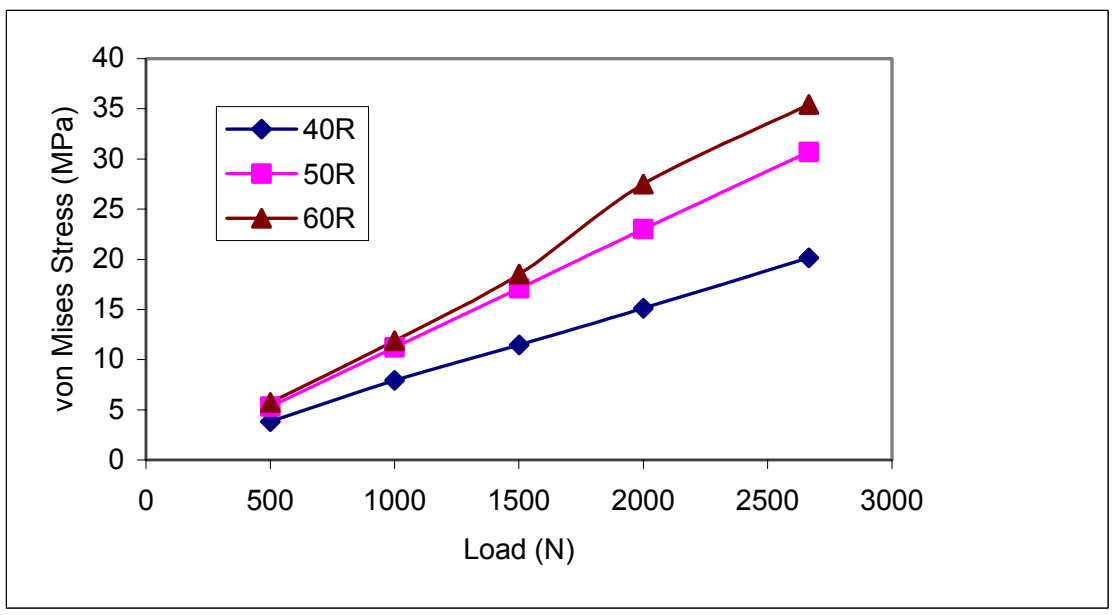

Figure 6: $\quad$ von Mises stress for different loads. 


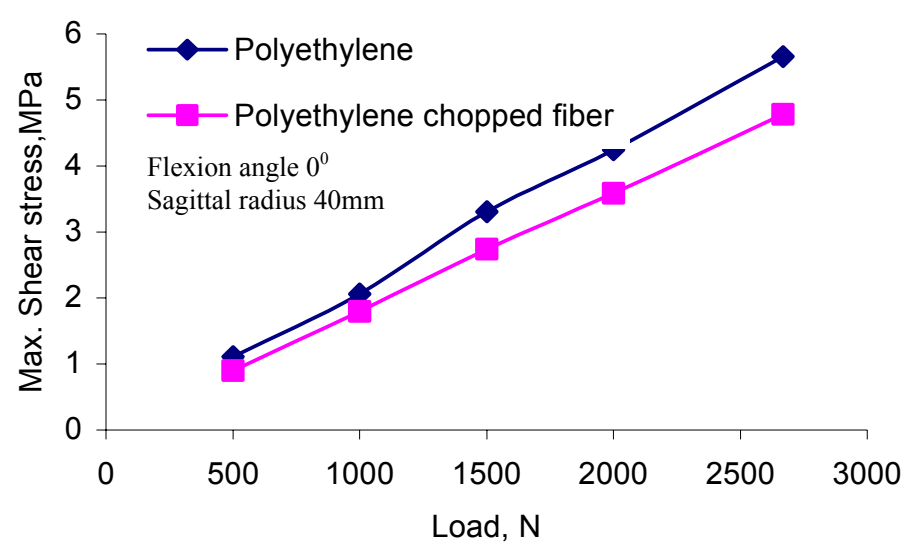

Figure 7: $\quad$ Maximum shear stress for different materials.

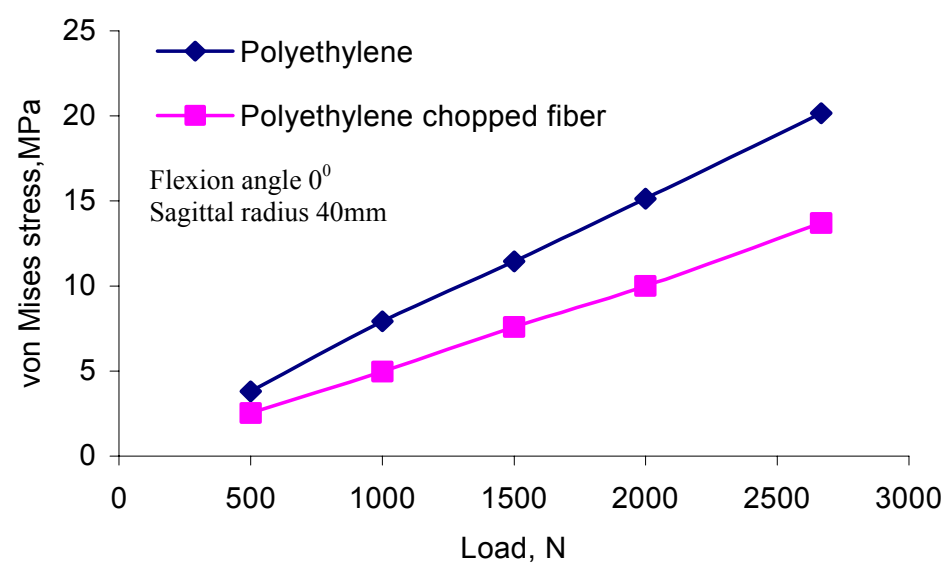

Figure 8: $\quad$ von Mises stress for different materials.

\section{Conclusion}

The stresses level at the interface of the tibia and femoral is lower for polyethylene chopped carbon fibre and alumina ceramic combination compared to polyethylene and alumina ceramic.

\section{References}

[1] Aaron Essner, Robert Klein, Michael Bushelow, Aiguo Wang, Michael Kvitnitsky, Ormond Mahoney. "The effect of sagittal conformity on Knee wear”, Wear, 255,1085-1092, 2003. 
[2] Louis E. DeFrate, Hao Sun, Thomas J. Gill, Harry E. Rubash, Guoan Li." In vivo tibiofemoral contact analysis using 3D MRI-based knee models", Journal of Biomechanics, 37, 1499-1504, 2004.

[3] Jason P. Halloran, Anthony J. Petrella, Paul J. Rullkoetter. "Explicit finite element modeling of total knee replacement mechanics", Journal of Biomechanics, 38, 323-331, 2005

[4] 4. Hood R. W.; Wright T. M.; Burstein A. H. "Retrieval analysis of total knee prostheses: a method and its application to 48 total condylar prostheses", Journal of Biomedical Materials Research, 17,829-842, 1983

[5] Dl Bartel, J J Rawlinson," Knee Joint Replacement During a Gait Cycle Using Explicit Finite Element. Analysis" Journal of Biomechanics, 35, 267-275, 2002.

[6] P S Walker and S Sathasivam, "Design forms of total knee replacement" Journal of Biomechanics, 30(2), 177-184, 1997.

[7] M. A. R. Freeman, V. Pinskerova, "The movement of the normal tibiofemoral joint", Journal of Biomechanics, 38, 197-208, 2005.

[8] Tammy L. Haunt Donahue, M. L. Hull, Mark M. Rashid, Christopher R. Jacobs, "A finite element model of the human knee joint for the study of tibio-femoral contact”, Journal of Biomechanical Engineering, 124, 273280, 2002.

[9] Stephen J. Piazza, Scott L. Delp, "Three dimensional dynamic simulation of total knee replacement motion during step-up task, Journal of Biomechanical Engineering, 123, 599-606,2001.

[10] Jean-Noel A. Argenson, Giles R. Scuderi, Richard D. Komistek, W. Norman Scott, Michael A. Kelly, jean-Manuel Aubaniac, "In vivo kinematic evaluation and considerations related to high flexion in total knee arthroplasty", Journal of Biomechanics, 38, 277-284, 2005. 